\title{
Regional Growth in the "New" Economy
}

\author{
Alan R. Winger*
}

\begin{abstract}
There is a large body of knowledge about the regional economic growth process that some would argue contributes little to the analysis of such growth in today's "new" economy. This argument is examined in some detail and shown to exaggerate the shortcomings of what might now be considered the mainstream view of how to study the economic growth process of regions. There are nevertheless some shortcomings in the mainstream view for which new paradigms might be needed. Possible directions for future research that will remedy some of the current deficiencies in the mainstream models are explored.
\end{abstract}

\section{INTRODUCTION}

Regional economic growth has a long history of research out of which has come a body of knowledge used by many as the underpinnings for studies of the growth potential of particular regions or urban communities. What we think we know about regional economic growth has changed over the years, which is not surprising in view of the academic interest in the subject and changes in the environment in which the growth has taken place. Environmental changes have been especially important in the development of our theories and models, a fact that augurs much more research in the future.

The economic world, as we all know, has been undergoing an abundance of environmental change. The deregulation of markets, globalization, an accelerated pace of innovation, growth in the importance of knowledge as a productive input, and some significant changes in how we communicate with one another are trumpeted as the major elements of this change. Not surprisingly, those on the firing line in this cauldron of change--business folks_talk about operating in a new economy. And those academics who concern themselves with business behavior and change are sketching out what they argue to be some of the major components of an analytic framework needed to analyze business behavior in this new economy. While those who are a part of the new economy and those who analyze it do not concern themselves directly with the regional or local implications of the change they study, if what they are telling us has substance, it clearly has bearing on the regional growth process.

This paper has several parts. The first part presents a synopsis of one view of the new economy-a view that emphasizes the nature of certain changes currently taking place in our information technologies. The second part points to some soft spots in this view, which raises questions about just how much it will contribute to the study of regional growth. A third part delves more deeply into the question of its potential contribution. The regional growth modeling 
implications of the answer given are taken up in the final section of the paper. Before beginning all this, a brief review of the major elements that make up the mainstream model is set forth.

\section{THE MAINSTREAM VIEW OF REGIONAL ECONOMIC GROWTH: A BRIEF REVIEW}

The mainstream view of the regional economic growth process has roots in demand-oriented macroeconomics. In its earliest stages, the focus was on product demands of firms in industries that exported what they produced locally-the economic base of a region. ${ }^{1}$ Export demand was considered to be important because it was not restricted by the size of the local market. Equally important were the multiplying effects of that demand that were reflected through local spending and industry linkages. ${ }^{2}$ Stimulating growth in this kind of model meant attracting industries that operated in export markets with rapidly expanding demands and/or increasing shares in less buoyant markets.

The composition of industries to be found in different places in this kind of a framework was a function of what a region had to offer in terms of access to markets and the cost and availability of its human, capital, and natural resources. The initial studies of what the supply variables in the model were focused on inputs that lie at the heart of the neoclassical model of economic growth, i.e., labor, capital, and technical change. ${ }^{3}$ Some of the early work in developing such a neoclassical model as applied to regions was done by professors Borts and Stein (1964), who, while concentrating their modeling efforts on labor, capital, and an interregional migration adjustment mechanism, included a demand variable as well. This provided us with one of the earlier versions of what we have now come to call the mainstream model of regional economic growth.

Mainstream models, as they were further developed, refined, and given empirical content, quickly became vehicles used to study regional growth potential and to make forecasts of likely outcomes. ${ }^{4}$ They became the bedrock of many earlier policy analyses aimed at figuring out what might be done--perhaps through local fiscal policies - to alter the growth path that market forces and existing policies seemed likely to deliver. As it turned out, the models delivered less to policy makers than promised, in part because they were never really up to the task for which they were being used. Our macroeconomic problems of the 1970s and early 1980s also created difficulties, showing the models to be less well-equipped to deal with economic turmoil than was initially believed. Another problem was the models' failure to deal effectively with agglomeration effects that had supplyside repercussions in many regions, especially urban regions.

\footnotetext{
${ }^{1}$ The basic elements of such a demand-oriented model were well described in a relatively simple and straightforward work by Charlie Tiebout done more than 35 years ago (Tiebout 1962).

${ }^{2}$ Richardson (1985) provides a detailed discussion of these multipliers as they were fitted into the demandoriented models of the 1970s and 1980s.

${ }^{3}$ The neoclassical growth model has its roots in the early work of Solow (1957).

${ }^{4}$ Roger Bolton (1985) provides a description of some of these models that were put together in the 1970 s and early 1980s.
} 
Regional researchers have by no means ignored agglomeration or scale economies. Indeed, these concepts have a long history in economics as well as in certain other disciplines. ${ }^{5}$ These effects have, however, resisted easy inclusion into growth modeling efforts, probably because of the difficulties of fitting something that is so dynamic and difficult to measure into the relatively simple analytical structures that underpin the mainstream model.

Research into agglomeration effects continues unabated, with much of the recent focus on knowledge spillovers and how they impact cost structures in regions where they are important. ${ }^{6}$ While we now know more about such spillovers, we are apparently still a considerable distance away from fitting that knowledge into our models of regional growth. That we are is a serious deficiency to those who talk about the new economy.

Precisely what is it that we need to understand and fit into our study of regional economic growth to make our models more relevant? There are academics publishing in business journals and business consultants writing books who, for some time now, have been promoting a view of what is happening that emphasizes the importance of innovation, particularly innovation that is altering how we communicate with one another in the business world. What do they tell us that is relevant to the regional growth process?

\section{ONE TALE OF THE NEW ECONOMY}

Many who study what they believe to be our entry into a new economic era focus on technology and the rapid pace of technical change argued to be much in evidence today. Economic change is, of course, a staple of life brought about to a large extent by changing technologies. Since the inception of science, the pace of technological change has accelerated, but it has not been a constant. It has come instead in waves, usually led by breakthroughs in one or a group of industries.? Over the past five to ten years, the information industry has led the way, giving us what some characterize as revolutionary change. The change is being diffused throughout the economy and it underlies much of the ferment and turmoil reported recently in the business and financial press.

Some who talk about the economy this way characterize it as a digital economy. ${ }^{8}$ They see it as an economy in which information is digitized and communicated through digital networks. The result is huge amounts of information compressed into very small spaces and transmitted over great distances at

\footnotetext{
${ }^{5}$ Marshall (1919) provided us with an early discussion of some of the elements that caused firms to concentrate their operations in certain places. Weber (1929) discussed and amplified some of these elements in his seminal work on firm location. Hoover (1937) contributed much in his development of some of Weber's (1929) ideas. Since then, a great many researchers from a number of disciplines have, through their work, contributed to our understanding of these economies, including Chinitz (1961), Jacobs (1969), and Krugman (1991).

6 See, for example, Saxenian (1993) and Gaspar and Glaeser (1998).

7 Schumpeter (1939) and Kuznets (1953) pretty well established that long waves or cycles of boom and bust are characteristic of market economies. Primarily through the work of Schumpeter (1939), we have come to believe that the source of these waves is spurts that occur in the pace of technological change. These spurts, in turn, are said to come into fruition through industries that were created or radically transformed by some significant innoyation (Ayers 1990).

${ }^{8}$ One of the more celebrated promoters of this view of the new economy is Don Tapscott (1996). See also Kelly (1998) and the U.S. Department of Commerce (1998).
} 
incredible speeds. What this has done, among other things, is to greatly enhance the role of knowledge in the economy. With instant access to relevant information, so much more can be done. What we do with the information increasingly involves putting knowledge content into what we produce and how we produce it.

Knowledge in this view of the economic world is the key input in production. Those who bring it to the process are the real assets of the producing firm. Amazon.com is frequently offered as the prototype of a business that typifies what is going on in today's real world. Here we have a company that owns little in terms of physical capital but has a capital valuation measured in billions.

Discussions of how all this works itself out in the way markets organize economic activity emphasize the impact of knowledge on market competition. Markets are said to be much more competitive and filled with pressures that are increasingly taking the form of quality rather than price competition. The basis of these pressures is innovation. Firms are more innovative in their quest for profits than they were. The aim is to bring new and/or better products to market more quickly than competitors. But doing this often means doing things in ways that frequently complicate the production process and give rise to the need for smarter inputs. Knowledge thus becomes critical to a successful operation in today's hypercompetitive markets.

More intense competition, innovation, and knowledge: these are the key parts of the new economy story. But they do not tell us everything. There is, some argue, something more fundamental going on here.

While the activity we find in firms on the cutting edge of today's technologies revolves around competition, innovation, and knowledge, it is also activity that frequently has an uncertain destination. In terms of particulars, the firms often involved do not know where some of their activities are headed. At best, what they have is a vision of the possibilities. There is a lot of haze that has to be worked through. As firms work their way through it, they find themselves operating in markets that are much less identifiable than traditional ones. They become involved with something that has many cloudy linkages in what is often characterized as a web of activities. These activities, furthermore, usually involve more than one firm, which adds to the complexity of the process and the uncertainty of the outcome.

Operating in this kind of environment is not really like competing in a traditional manufacturing industry where the market is well-defined. Take the automobile industry as an example. While firms in this industry currently engage in a good deal of research and development work, the precise outcome of which is often uncertain, industry leaders have a pretty good idea of its destination. The R\&D will likely improve the automobile in ways that make it more competitive.

This is not the case with a lot of what we are now doing in some areas of microelectronics with respect to the way in which we communicate information. Consider by way of example the effort now going into the development of the socalled system on a chip. The aim is to come up with computer chips that have 
multiple applications in different communication devices that will establish what are now important absent linkages in our emerging communication networks. While this may sound specific, we are talking about something that currently has an undefined architecture. We do not really know now what some of those communication devices are or might be and how all of them should be linked together. There is a good deal of uncertainty about a system that may be still, in part, in the dreaming stage.

Arthur (1996, pp.103-105) has argued that one strategy for success in such areas of activity is one that mimics what we do in a casino. In the casino, we not only have to have the skills necessary to play any of the games that are there, we have to choose the game we want to play. Knowledge about any of the games that we might play is critical, but we must also have insight into the many games that can be played. This is a more difficult matter. It requires some notion of the big picture, which for most of us is something that is often difficult to grasp. Those who have it are sometimes called visionaries. To exploit that vision, they must be willing to take risks--sometimes big risks.

It almost goes without saying that success in putting these kinds of elements together requires an organization that is flexible and agile. The hierarchical structure of the industrial age just will not work. What is needed is a horizontal organization with teams of skilled operatives who have the authority and ability to act decisively when the need arises. Some have characterized this as an organization similar to what the military uses for its commando operations.

If our economic world is anything like this description of it, we are dealing with an economy that should be responding to a set of rules that are different from the traditional ones. While the demand for what is being produced should not be ignored in this world, it is obviously less important than the activities of the producing firms. What is important is bringing together highly skilled and welltrained folks in a way that reflects a sensible understanding of the big picturethe vision-and willingness, indeed even an eagerness, to take risks. These are the kind of operations that are most likely to be successful. They are the activities that are the engines of growth in the new economy.

Also important in this new economic world is the creation of a learning environment that fosters the development of a workforce made up of knowledgeable workers who are capable of dealing with a broad range of problems in creative ways. This may amount to a radically different setting of relationships between firms, employees, suppliers, and customers. That environment also has to be one that encourages the development of entrepreneurial interests and talent. While those who spin this particular new economy tale do not concern themselves with the details of how regions or localities might best participate in the growth of this economy, it is clear from their view of the economic world that establishing an environment that fosters learning and entrepreneurial spirit is the key. 


\section{SOME SOFT SPOTS IN THIS TALE}

Nobody disputes the presence of change in our economic world. It is all around us. The microchip, for example, is altering significantly what we can do with information, and the recent digitization of that information is bringing about substantial changes in the way in which we communicate with one another. There are also developments in biotechnology that present opportunities for us to do much more in a number of areas, including health, agriculture, and some manufacturing. There is also a good deal of evidence of change in how we organize ourselves in the businesses that use all of those new technologies. Just what is coming out of this, however, is another matter.

\section{Just How Much Innovation?}

Consider first the question of just how much change through innovation is occurring. Although this concept raises difficult measurement problems, ${ }^{9}$ a central part of it has to be the R\&D activities undertaken in both the private and public sectors of the economy. When we look at measures of $R \& D$, however, there is no indication of any recent acceleration. $R \& D$ expenditures are at about 2.5 percent of gross domestic product, as they have been for the past 40 years. While $R \& D$ spending may fail to give us insight into a number of elements of the process of technological change, it is an important part. One would expect some increase in spending if innovation was playing as critical a role in how we use our resources as spelled out in this new economy tale.

\section{Just How Much Benefit?}

Suppose we had a more comprehensive measure that showed an acceleration in the rate of adoption of new technologies. This could be happening. Even if it were, it would not necessarily mean we are undergoing structural change of the kind that is improving the economic well-being of the nation. This appears to be a part of the picture drawn by those who tell us all about the new economic world. For this to be happening, the adopted technologies would have to be making us more productive, which has to show up in our measures of productivity. The problem is that there is as of yet no convincing evidence that it is. Indeed, prior to the recent revisions of the national income data, the evidence was to the contrary. With the old numbers, the productivity gains-measured in terms of output per hours worked-were during the years 1973 and 1997 only about one-half of what they were between 1965 and 1973. These gains did accelerate in the middle part of the 1990s, but this could be explained without concluding that the longforecasted productivity benefits of the computer were coming to fruition. ${ }^{10}$

Now come the recent revisions of the national income account data, which show productivity growth to have been greater in the earlier period -0.2 percent per year-and considerably more in the latter half of the 1990s-up 0.4 percent per

${ }^{9}$ Sirilli (1997) provides a lengthy discussion of these problems and what we might be able to do about them.

10This I take to be the conclusion of three recent papers (Carlson and Schweitzer 1998; Triplett 1999; Arnold and Dennis 1999). 
year. Initial inquiries of the new numbers nevertheless suggest that close to half of the recent gains came from a cyclical effect and that the other half came from increased productivity in a very restricted portion of the economy, i.e., computers and software.11 This is not the kind of productivity picture one would expect if radical change of the kind being postulated was underway.

To be sure, questions can be raised about just how much we get from our productivity measures. They do not adequately account for real output changes in the service sector, the dominant area of activity in the economy. There are also questions that can be raised about how they handle qualitative changes in products coming out of the production process, another important element in the new economy view of the world. Then there are all those anecdotal reports of the rapidly growing number of business Internet applications said to be generating a number of important cost and revenue benefits. ${ }^{12}$ Anecdotes are, of course, data of a sort.

Suppose our productivity measures do in fact understate the impact of the computer and its links to telecommunication technologies on real output, which they probably do. There are some reasons for arguing that the understatement is not as great as the new economy buffs allege.

First, the centerpiece of the process said to be changing the economy-the computer and its related equipment-is not all that important in the current scheme of things. While investment in these things is the fastest growing segment of the physical capital investments of businesses, it currently only accounts for maybe 10 to 15 percent of the total. We still need a lot of old-fashioned fixed investment--plants, trucks, office buildings, malls, and manufacturing machinery-to keep the economy going. What is physical is apparently still much more important than what is virtual.

Second, computer technologies currently give us less than is often claimed. While we are working towards open standards, we are no where near achieving them. This means that what we do with the technology is not always easily fitted into what we are trying to accomplish. There are learning costs that diminish productivity and costs due to obsolescence policies, especially on the software side of the computer business. Since software is not a perishable good, firms in the industry regularly try to expand sales by inducing customers to buy updates. But this necessitates more learning, which cuts down on productivity.

Third, by no means are all of our computer activities productivity enhancing. A good deal of what comes onto the market gets customers engaged in activities that amuse or satisfy idle curiosities. Purposeless surfing of the Internet, participating in chat groups, and the playing of games have little if any positive impact on productivity.

Finally, there is the problem of information overload. The aim, of course, is to assemble and transfer boatloads of information at lightening speeds. But doing so creates a problem if the ability to process the information lags behind the ability

12 The Economist (1999) put together a good summary of some recent illustrations of these activities. 
to assemble it, as it apparently commonly does. While this is by no means an insurmountable obstacle, it is a problem now in more than a few instances. ${ }^{13}$

Some who speculate about the consequences of our emerging information technologies argue that while all this may be true, Rome was not built in a day. It takes time to incorporate things expected to transform the economy in a radical way. ${ }^{14}$ Electricity, for example, remained largely out of the economic loop for close to a century after its discovery. With what is on our information technology platter, we appear to be dealing with something that will have an economic impact that may well dwarf that of electricity. Consider now that we have only been working at developing the needed infrastructure for the past five to ten years. The best is clearly yet to come.

The point is a good one, but it is well to remember that the argument has been made before, leading to forecasts that turned out to be far off the mark. Kahn and Wiener's (1967) technology-based forecast of life in America in the year 2000 is a case in point. Relying heavily on their views about the timing of upcoming impacts of foreseeable technological change, they forecast that living standards would double by the end of the century and that this would happen in the face of a sharp decline in the amount of time we worked-a 39-hour work week with 13 weeks of vacation per year.

What most forecasters often do is greatly exaggerate the likely consequences of anticipated changes in our technologies, probably because they are enamored with what they see and others do not. Whatever the reason, it is important to keep in mind that forecasts of a new economic era are not new and most of the earlier ones were of periods that turned out to be much less revolutionary than forecast. What this implies is the need for caution in statements made about radical change in the economy.

\section{WHAT IS REAL? WHAT IS NOT?}

Clearly, there is significant change underway in the way in which we assemble and use our economic resources in many parts of the economy. There are well-publicized changes taking place in many firms. Many of them have downsized their operations and outsource a lot of what used to be done in-house. Layers of the old bureaucracy have also been removed and more of the work is now done in teams. Most business organizations are now more agile and flexible in their operations.

The technologies that have given us the Internet and the World Wide Web are clearly changing the way we carry out information-related activities in business. We now have something that gives us instant access to a great deal of information and allows us to communicate with many more people over great distances at a much lower cost than before. This means communication costs are ${ }^{13}$ Schultze and Vandenbosch (1998) argue that information load is a serious problem, the dimensions of which can be reduced by the intelligent application of groupware technology. But they also note that the successful use of such technology in the sense of keeping information users from being overwhelmed by data inhibits the potential positive effects the groupware is designed to deliver.

14Makridakis (1995) is one of those who argue that there is an information revolution under way, but that we will not see the full impact of it for some time. 
much less of a constraint on some of the things we do, which should influence where we do them.

The most publicized examples of this are found in information-intensive activities such as financial services. The influence of the Internet on the certain financial transactions of households is well known. Most of us know that many personal investors no longer find it necessary to be physically near a broker. The rapidly developing Internet brokerage services provide needed information and the ability to put it to use quickly at very little cost. Since there is no need to go anywhere to do this, those who provide the service do not have to worry about being near the user. Market access loses its importance.

The big conversion to what is now being called electronic commerce, however, is not with individuals in information-sensitive markets; it is with businesses dealing with their information problems (The Economist 1999). The use of computer technologies to deal with accounting and inventory problems has been going on for some time now. What the development of the World Wide Web has done is to allow these efforts to spill over to connections with other firms.

Much of what is done in business, of course, involves the transmission of information from one part of a process to another, and there are a lot of these information linkages. Some of the earlier efforts as the world of the Internet was developed were aimed at establishing linkages with certain information-sensitive inputs outside the firm. Some computer programming activity, for example, was parceled out by American companies to operators in places like India and Bangladesh. To the extent that programmers in these places were competent to do the job, as they were in many instances, Web connections made it possible for them to do it at costs that were very attractive. More recently, the emphasis has been on developing Web linkages with all the other firms that supply parts or services to a business. Those in business and those who study business behavior talk about this establishing more cost-efficient supply chains.

Exactly how much business-to-business electronic commerce will be carried out in cyberspace remains to be seen. All indications are that it will be a great amount. The potential here is huge. But the outcome in most instances will not bring about fundamental changes in the way most business operate. We are now beginning to live in the world the new economy gurus talk about, and for those of us who live in the middle part of America, the economy in no sense seems to be radically different from what it was a decade or two ago. While there are obvious signs of change, most people in this part of the world continue to spend the largest part of their money on material things and services provided to them near where they live. Moreover, most of what they consume is produced pretty much where and in not too different a way it has been for sometime now. Despite reports of the globalization of markets, only about 15 percent of what is consumed has been produced abroad. And despite the talk about mass customization and the disappearance of Fordist methods of production, much of what is consumed in middle 
America comes out of processes that have traditional scale effects. ${ }^{15}$ For those who do not live in the Silicon Valley, life, while it has changed, is by no stretch of the imagination radically different than it was a decade or two ago.

What we have in most places are economic circumstances and modes of operation much like those in the middle part of America. Many of the firms with operations in Ohio, for example, are there because of the state's access to a large part of the nation's population. That a big market can be served well from Ohio is still important to many firms. Some firms are also in Ohio because of the ready supply of certain kinds of labor as well as the benefits they can get from static agglomeration economies in its large cities. Ohio, like other Midwestern states, has comparative advantages in traditional things-advantages that underlie a good deal of its current growth potential. But now that is only a part of the story.

The recent success of a good many firms in any one or all of these statesor most other states-stems in part from the adjustment these firms have made to the reality of operating in more dynamic and competitive markets. They are now more focused on innovative product improvement and cost reductions, with efforts that are concentrated largely around innovations coming out of information technologies. These are the innovations creating opportunities for change in such information-centered activities as accounting, inventory management, legal affairs, R\&D, purchasing, and marketing. Thus, even though many firms continue to operate as a part of a "traditional" industry, they do not do it exactly as they have in the past. And the way in which they do things now helps account for the success they are currently having. ${ }^{16}$

All of this is true. But it is also true that, in the lion's share of their operations, most of these firms are still constrained in what they do by geography. Where their customers are, where the resources they use are-these are still very important matters to a great many firms.

There is, to be sure, the potential for radical change in the emerging digital technologies. The geographic constraints that influence what we do today could be significantly diminished. But this is not very likely to happen any time soon because of one big impediment. Electronically mediated communication as it exists today still lacks much of the richness of face-to-face business situations. Current research still indicates that close encounters with coworkers, suppliers, and customers is the most effective way of dealing with problems that do not have simple answers. ${ }^{17}$ And this is the kind of problems that will dominate our business concerns as we try to adjust to the technologies of the times.

${ }^{15}$ This is not to say that we are not getting more customization in the output of industry. There is indeed evidence of some recent proliferations of the products and services going to us as consumers (Federal Reserve Bank of Dallas 1998). But the number of different kinds of products and services in relation to the number of consumers suggests a lot of traditional scale effects in the production of what we consume.

16In looking at a sample of manufacturing firms located in the Midwest, Richard Florida (1996) concluded that their recent ascent to profitability was the result of a high rate of adoption and diffusion of new technologiesespecially information technologies-reflected mainly in organizational changes.

17 Most of the current research focused on the issue of face-to-face versus computer-mediated communication is found in the field of communication. While there is much that remains to be done with the inquiries that have started, the early conclusion is, not surprisingly, that face-to-face communication is richer and more capable of dealing with problems that involve complex interactions among the folks involved (Trevino, Duft, and Lengel 1990; Walther 1996; Bordia 1997). 


\section{IMPLICATIONS FOR THE STUDY OF REGIONAL ECONOMIC GROWTH}

Suppose we agree that in the foreseeable future most of us are still going to be living in a world in which houses, cars, big appliances, and certain kinds of soft goods and locally produced services dominate household budget decisions. And while production processes will continue to change as electronic connections increase in importance, physical capital, labor, and land will remain as the dominant inputs in production in most places. Furthermore, having some operations near to the consumer will not lose its importance in many businesses. What this implies are economic growth parameters for most regions that are not all that different from what they have been.

But there will be exceptions. The mainstream model will be less helpful when applied to regions populated with firms operating on the cutting edge of some prolific technology. New paradigms may be needed. We will have to pay more attention to what business behavior academics tell us about how these firms behave and the market conditions in which they operate. When the setting is one of continuous innovation, knowledge intensive activity, and highly uncertain outcomes, a focus on things such as learning channels, vision, and entrepreneurial zeal might be warranted. A concern with product demand seems less pressing when we do not have a clear view of what that product is going to be. And the cost concerns of the mainstream model may be less than helpful in giving us insight into the operating behavior of firms consumed by the quest for operating agility and flexibility. What we are being told about operating elements such as cross-functional teams, benchmarking, strong work incentives, and outsourcing should perhaps be given more emphasis.

The problem here, of course, is to find a conceptual framework within which to fit all these operating elements. Arthur (1996) has provided one such framework, the focal point of which is the notion of increasing returns. Teece (1998) also addressed the question and provides links from his notions back to main stream economics. Shapiro and Varian (1999) provide insights into the elements of a successful business operating in the information economy that build upon traditional microeconomic concepts. Finally, there is the work some urban and regional researchers have undertaken in trying to decipher the mysteries of the linkages developing between firms that seem so important in some economic settings. Some of this provides us with other ways of looking at business behavior in the new economy setting. ${ }^{18}$

What is important to remember here is that we are talking about activity that still constitutes only a relatively small proportion of the total. Indeed, there are still things we do in ways that are light years away from what those high-hightech firms now do. Those who give us haircuts, clean our offices, or prepare our

\footnotetext{
${ }^{18}$ Storper (1997) is one of these, trying as he has to develop the notion of "untraded interdependencies" into a framework that will help us understand better the engine of growth in agglomerations of economic activity found in certain places.
} 
food continue to do so much as they have for some time now. Surely, we do not have to worry about new paradigms here.

What is really important in most regions, of course, is activity that falls somewhere between these two extremes. This is activity that is still importantly influenced by traditional location factors, such as market access, labor costs, and availability and agglomeration economies. But it is also activity that takes place in an environment that embraces some of the elements and pressures found in that high-high-tech world. Digital technologies, as noted above, are providing opportunities to alter in cost-effective ways a wide range of information-related activities that are a part of what most firms do. The opportunities are there, as are competitive pressures that prod businesses to take advantage of them. That firms are responding is surely reflected in the recent growth of electronic commerce between businesses.

There is also the competitive pressure for product innovation. While the markets in which these firms operate still embrace price as a competitive factor, that competition focus is shifting more toward quality. Getting to the market first with something that can be differentiated from and is better than what competitors offer seems to be becoming more important. Operating successfully in such an environment requires more smarts, which implies more emphasis on knowledge and learning in the important strategic and tactical decisions that have to be made. ${ }^{19}$

Obviously, it behooves localities anywhere in today's world to pay more attention to the knowledge factor in firm operations. Survival and prosperity even in markets populated with firms that continue to be influenced by traditional location advantages require, increasingly, the need for ever-improving products brought quickly to market and/or the need for cost reductions. And achieving these things in tomorrow's technological setting will require greater knowledge inputs. Providing a good learning environment is, in today's world, a potential edge that cannot be ignored. But, for most regions, it would be equally foolhardy to ignore what we know about the growth process that is wrapped up in mainstream models.

In most regions, an emphasis on comparative advantage in terms of market access and traditional supply factors is not misplaced. But traditional concerns with industry revenue and cost factors as they come to bear on the competitiveness of a region need to be expanded to encompass the elements of successful operation by individual firms in that region.

How we might best do this is by no means clear from the work of those who study business behavior in today's environment of change. Most discussions of the questions of what businesses do today and why are more in the nature of prescriptions rather than explanations. What we get are ideas built around popularized terms, such as downsizing, benchmarking, reengineering, just-in-time inventory management, empowerment, cross-functional work teams, the outsourcing of noncore functions, and quality. While there may be a kernel of useful${ }^{19}$ For one insightful view of what is involved in such a knowledge economy see Stiglitz (1999). 
ness in the ideas that underlie these terms, even as prescriptions none of them has delivered what they promised when first promulgated and promoted. At a very descriptive level, what seems to be happening is success being achieved through careful and intelligent experimentation. What is now being reported as the way to get to the promised land is experimentation-throw out what does not work and keep what does. ${ }^{20}$

All this clearly does not take us very far in the quest for knowledge of the elements of a successful firm response to the competitive pressures firms face in the markets in which most currently operate. While I have by no means touched upon all the elements that underlie the current dynamics of these markets, ${ }^{21}$ how firms use the opportunities provided by information technologies to cope with market pressures is an important part of the success stories. What this means is that knowing something about the emerging world of "e-business" should become an important concern of those who model the growth process of most regions. In this regard, Shapiro and Varian (1999) provide an interesting introduction to the elements of a successful operation in the electronic marketplace. If we can build successfully upon what they have started, the question then becomes how to fit this knowledge into a mainstream model. This will, I am sure, become a major problem confronting those who choose to tussle with regional growth questions in the future. It is also one that I plan to address in my remaining years as an active participant in the inquiries that will be made into the process of regional economic growth in the new economy.

\section{REFERENCES}

Arnold R., and R. Dennis. "Perspectives on Productivity Growth." Business Economics 34 (2) (April 1999), 7-12.

Arthur, W.B. "Increasing Returns and the New World of Business." Harvard Business Review 74 (4) (July-August 1996), 100-109.

Ayers, R.U. "Technological Transformations and Long Waves: Parts I and II." Technological Forecasting and Social Change 36 (1990), 1-37; 111-137.

Bolton, R. "Regional Econometric Models." Journal of Regional Science 25 (1) (1985), 495-521.

Bordia, P. "Face-to-Face Versus Computer-Mediated Communications: A Synthesis of the Experimental Literature." The Journal of Business Communications 34 (1) (1997), 99-120.

Borts, G.H., and J.L. Stein. Economic Growth in a Free Market. New York: Columbia University Press, 1964.

Carlson, J.H., and M.E. Schweitzer. "Productivity Measures and the 'New Economy.' " Federal Reserve Bank of Cleveland Economic Commentary (June 1998), 1-4.

20The Xerox Corporation is now being touted as a model for others to follow in today's economic world. Apparently, Xerox's current success is the result of careful experimentation. As its president has said, "We've tried out lots of different stuff and thrown out what didn't work. But the ones that stuck had an absolutely profound impact on the way in which our companies perform" (Pearlstein 1998).

21 What is obviously missing is a discussion of globalization and how it is influencing competitive pressures in regional markets. Also missing is a discussion of the impact of changes in the organization of industries. 
Chinitz, B. "Contrasts in Agglomeration: New York and Pittsburgh." American Economic Review: Papers and Proceedings 51 (1961), 279-289.

The Economist. "The New Economy: Work in Progress." 24 July 1999, 21-24.

Federal Reserve Bank of Dallas. "The Right Stuff: America's Move to Mass Customization." 1998 Annual Report (1998), 3-26.

Florida, R. "Regional Creative Destruction: Production Organization, Globalization and the Economic Transformation of the Midwest." Economic Geography 72 (3) (1996), 314-344.

Gaspar, J., and E. Glaeser. "Information Technology and the Future of Cities." Journal of Urban Economics 43 (1) (January 1998), 136-156.

Gordon, R. "Has the New Economy Rendered the Productivity Slowdown Obsolete?" 1999. Available online at http://faculty-web.atnwu.edu/economics/gordon. Hoover, E.M. Location Theory and the Shoe and Leather Industries. Cambridge, MA: Harvard University Press, 1937.

Jacobs, J. The Economy of Cities. New York: Vintage Press, 1969.

Kahn, H., and A.J. Wiener. The Year 2000: A Framework for Speculation on the Next Thirty-Three Years. New York: Macmillan, 1967.

Kelly, K. New Rules for the New Economy. New York: Viking Press, 1998.

Krugman, P. Geography and Trade. Cambridge, MA: MIT Press, 1991.

Kuznets, Simon S. Economic Change: Selected Essays in Business Cycles, National Income, and Economic Growth. New York: Norton, 1953.

Makridakis, S. "The Forthcoming Information Revolution: Its Impact on Society and Firms." Futures 27 (8) (1995), 799-821.

Marshall, Alfred. Industry and Trade: A Study of Industrial Technique and Business Organization. London: Macmillan and Co., Ltd., 1919.

Pearlstein, S. "Reinventing Xerox." The Washington Post National Weekly Edition (1998), 6-9.

Richardson, H. "Input-Output and Economic Base Multipliers: Looking Backward and Forward." Journal of Regional Science 25 (1) (1985), 607-661.

Saxenian, Anna Lee. Regional Advantage: Culture and Competition in Silicon Valley and Route 128. Cambridge and London: Harvard University Press, 1996.

Schultze, U., and B. Vandenbosch. "Information Overload in a Groupware Environment." Journal of Organizational Computing and Electronic Commerce 8 (2) (1998), 127-148.

Schumpeter, Joseph A. Business Cycles: A Theoretical, Historical, and Statistical Analysis of the Capitalist Process. New York: McGraw-Hill, 1939.

Shapiro, C., and H.R. Varian. Information Rules: A Strategic Guide to the Network Economy. Boston: Harvard Business School Press, 1999.

Sirilli, G. "Science and Technology Indicators." In G. Antonelli and N. Deliso (eds.) Technological Change, 281-306. London: Routledge, 1997.

Solow, R. "Technical Change and the Aggregate Production Function." Review of Economics and Statistics 39 (1957), 312-320.

Stiglitz, J.E. "Public Policy for a Knowledge Economy." January 27, 1999. 
Storper, M. The Regional World: Territorial Development in a Global Economy. Perspectives on Economic Change. New York: Guilford Press, 1997.

Tapscott, D. The Digital Economy. New York: McGraw-Hill Publishing Company, 1996.

Teece, D.J. "Capturing Value from Knowledge Assets: The New Economy, Markets for Know-How and Intangible Assets." California Management Review 40 (3) (1998), 55-79.

Tiebout, C. The Community Economic Base Study. Washington, D.C.: Committee for Economic Development, 1962.

Trevino, L., R. Duft, and R. Lengel. “Understanding Manager's Media Choices: A Symbolic Interactionist Perspective." In J. Fulk and C. Steinfield (eds.) Organizations and Communication Technology. Newbury Park, CA: Sage Publications, 1990.

Triplett, J.E. "Economic Statistics, the New Economy, and the Productivity Slowdown." Business Economics 34 (2) (April 1999), 13-24.

U.S. Department of Commerce. The Emerging Digital Economy. Washington D.C., 1998.

Walther, J. "Computer-Mediated Communication: Impersonal, Interpersonal and Hyperpersonal Interaction." Communications Research 23 (1) (1996), 3-46.

Weber, A. Theory of the Location of Industries. Chicago: University of Chicago Press, 1929. 
